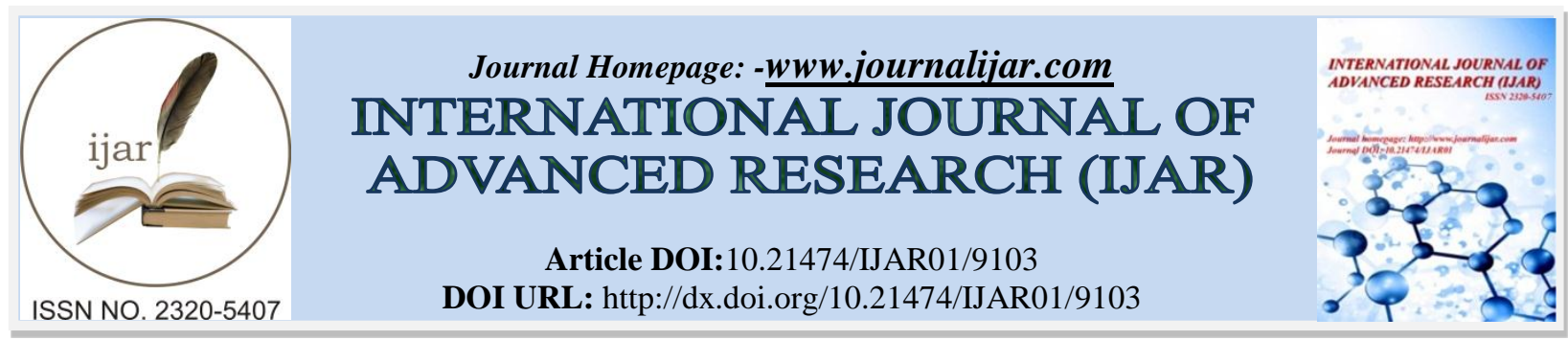

RESEARCH ARTICLE

\title{
LABORATORY PROFILES OF LIBYAN PATIENTS ON HEMODIALYSIS: A RETROSPECTIVE STUDY IN TWO MAIN HOSPITALS IN BENGHAZI CITY.
}

Salma A. Bukhatwa, Wafa M. Almajbri, Waed T. Alzuwawi, Turkeya Y. Ellgeryni And Narges M. Kablan. Department of Pharmacology \& Toxicology, Faculty of Pharmacy/ University of Benghazi, Benghazi, Libya.

\section{Manuscript Info}

Manuscript History

Received: 20 March 2019

Final Accepted: 22 April 2019

Published: May 2019

Key words:

Hemodialysis, Adults, Laboratory profiles, Libyan patients.

\section{Abstract}

Libya has a high prevalence of risk factors for chronic kidney disease. The majority of Libyan patients with end-stage kidney diseases remain dialysis-dependent. Regular assessment of laboratory parameters is the only way to reduce the risk of mortality in chronic kidney disease patients.

Current study aimed at analyzing laboratory profiles of Libyan patients on hemodialysis and admitted to Nephrology Units in two main hospitals; Benghazi Medical Center and Al-Hawari Hospital in Benghazi -Libya, during the period $3^{\text {rd }}$ July to $7^{\text {th }}$ August 2016.

A structured form was used to record data collected from patients' files. Collected data included admission date, medical history of patient, treatment history of the patient and importantly laboratory tests' results, specifically white blood cells (WBC), hemoglobin (HB), phosphate, calcium, sodium, creatinin, urea, albumin and glucose.

Males represented $68 \%$ of study sample, taking $\mathrm{n}$ consideration that $40 \%$ of study sample started dialysis in the last 4-6 years. There was a significant difference between the values of (WBC, HB, phosphate, calcium, sodium, creatinin, urea, and glucose) at time of measurement compared to values before starting dialysis.

Patients on maintenance dialysis in Libya have high incidence and prevalence of hypertension, hyperphosphatemia and anemia. Actions need to be taken to improve dialysis patients' care and also the choices of their medications.

Copy Right, IJAR, 2019,. All rights reserved.

\section{Introduction:-}

Libya has a high prevalence risk factor for chronic kidney disease such as obesity, diabetes \& hypertension. ${ }^{1,2}$ End stage kidney disease (ESKD) is a major health problem in Libya. The leading causes of ESKD in Libya are diabetic kidney diseases, chronic glomerulonephritis, hypertensive nephropathy and congenital/heredity disease. ${ }^{3}$ The most frequent co-morbidities are hypertension, obesity and metabolic syndromes. ${ }^{3}$

In Libya maintenance dialysis therapy is funded by public health care sector, but there is no national renal registry. ${ }^{4}$ Nevertheless, Alashek et al. 2012, succeeded to develop the first comprehensive description of the epidemiology of dialysis-treated ESKD in Libya. ${ }^{5}$ Also, Alashek et al. 2013, succeeded to provide the first comprehensive analysis of survival in Libyan dialysis patients. ${ }^{6}$ 
Maintenance dialysis therapy for ESKD is the commonest mode of renal replacement therapy as kidney transplantation is limited by lack of cadaveric donors. ${ }^{7,8}$ Regular assessment of laboratory parameters is the only way to reduce the risk of mortality in chronic kidney disease patients.

This study aims to analyze and discuss clinical pattern of dialysis patients in Benghazi city- Libya.

\section{Materials and Methods:}

This is a retrospective study included all patients diagnosed with kidney problem and underwent hemodialysis during the period $3^{\text {rd }}$ July to $7^{\text {th }}$ August 2016 in two main Hospitals in Benghazi city - Libya; namely Benghazi Medical Center (BMC) and Al-Hawari Hospital. All patients diagnosed with kidney problem and underwent hemodialysis during the period of study and admitted to Nephrology Units at BMC \& Al-Hawari Hospital were included in this study. The study population consists of all dialysis patients, who started a course of hemodialysis treatment at any of the two hospitals and took their medication and followed up by doctors and nurses until completion of their treatment. Patients transferred out of the hospital and/or completed their treatment in another health facility, patients less than 18 years old and referred to children hospitals and patients died before time of study were all excluded from the study. The total number of patients included in this study was 26 . Collected data from medical records of the 26 patients included both demographic data \& laboratory tests' results. Demographic data included age, gender and body weight of patients. The blood pressure as recorded in the case sheet and presence of any chronic disease were noted. The treatment history, drug history, duration, frequency of hemodialysis and lifestyle factors were noted as well.

Statistical Package for the Social Sciences (SPSS) version 15.00 Software package (SPSS Inc., Chicago, IL, USA) was used for the analysis of results. Chi-square test, Student t-test and one- way ANOVA were used as whenever appropriate, with $P$ value less than 0.05 was considered as significant.

\section{Results and Discussion:-}

Study was conducted in two main hospitals; namely BMC and Al-Hawari hospital located inside Benghazi city; the biggest city in the Eastern region of Libya. All hemodialysis cases admitted to the Nephrology Units in these two hospitals during the period July-August 2016 were included in this study according to criteria presented in the methodology section.

Patients underwent dialysis often have substantial comorbidity as a result of advanced age and underlying cause of ESRD and associated therapy. Renal disease patients included in this study had a mean age around 45 years, which is less than that reported from other countries such as 53 years in Saudi Arabia SCOT data 1999, 52 years in the European registry data, or 58 years in the US registry data. ${ }^{9}$ Mean age of patients receiving dialysis in Libya, has been always lower than most developed countries.

According to current study, males were more affected by kidney disease than females, noting that females were on average of 1.75 years younger than males $(44.25 \mathrm{y}$ vs $45.59 \mathrm{y})$ (Table 1$)$.

According to current study, the mean serum urea and creatinin values are high confirming the chronic kidney problem status of study subjects.

In spite of the fact that there were more patients within the 40-49 age group of this study but it is interesting that the number of patients within 20-29y age group was higher than number of patients in any of the 30-39y, 50-59y, 60$69 \mathrm{y}$ or 70-79y age groups (Figure 1). In spite of the fact that sample of current study is small but still this figure needs to be investigated as it gives a warning alarm regarding the appearance of ESKD in younger age than expected (Figure 1).

Most of patients have hypertension which appeared in $68 \%$ patients of study sample. Hypertension is a common result and frequent cause of chronic kidney disease. It may be prevented by adequate treatment, thereby preventing a further decline in renal function that may causes kidney failure.

Patients started dialysis since 1-2y, 2-4y, 4-6y, 6-8y, 8-10y,10-12y, and >12y represented $24 \%, 12 \%, 40 \%, 12 \%$, $4 \%, 4 \%$ and $4 \%$ respectively of study sample (Table 1 ). The reason that $40 \%$ of patients underwent hemodialysis for 
4-6 y is that kidney transplantation in Libya is limited by the lack of cadaveric donors and limited availability of suitable living-related donors. ${ }^{7,8}$ Current study shows the presence of hyperphosphatemia in hemodialysis patients (Table 2). Despite the remarkable improvements made in dialysis techniques over the years, phosphate control has not been substantially improved. In addition, variances in dialytic removal of phosphate, enteral phosphate absorption unexplained by diet or vitamin D intake, and binder efficacy may account for hyperphosphatemia in dialysis patients rather than non-adherence to therapy. Hypocalcemia occurs as a consequence of hyperphosphatemia and decreased calcitriol. A diagnosed kidney is incapable of excreting phosphate synthesizing calcitriol. Hyperphosphate lead to stimulation of parathyroid gland causing PTH release. The increased phosphate causes hypocalcemia by precipitating with calcium and forming calcium hydroxyapatite. Hyperphosphatemia is usually associated with a greater cardiovascular morbidity and mortality.

All subjects in this study had moderate (WHO classified) anemia with mean hemoglobin concentration around $9.7 \mathrm{~g} / \mathrm{dL}$ at start of dialysis and $8.7 \mathrm{~g} / \mathrm{dL}$ at time of study. This is due to reduced level of the hormone erythropoietin which is produced by kidney and regulates red blood cells. Also, some other factors were identified as a cause of anemia including, hemolysis, homeostasis phlebotomies and trapping of blood in the dialysis apparatus. Hemoglobin values should be corrected to prevent secondary complications, like for example left ventricular hypertrophy, cardiac failure, exercise intolerance and defective cognitive. ${ }^{10-14}$

Current study showed low serum sodium level at time of dialysis compared to its level at beginning of dialysis. In previous studies low serum sodium has been reported as an independent predicts of higher risk of infection in maintenance hemodialysis patients. Also, previous studies reported greater risk of mortality with low or low- normal serum potassium levels. ${ }^{15}$

\section{Conclusion:-}

Patients on maintenance dialysis in Libya have high incidence and prevalence of hypertension, hyperphosphatemia and anemia. Actions need to be taken to improve dialysis patients' care and also the choices of their medication.

\section{Recommendations:}

Regular assessment of laboratory parameters is the only way to reduce the risk of mortality in chronic kidney disease patients. Anemia should be assessed and patients should be given erythropoietin stimulating agent as nontherapy depending on the stages of chronic kidney disease and it is also recommended to monitor serum calcium and phosphate. Hypertension is one of the primary causes of chronic kidney disease, then increasing the awareness of people to improve their lifestyles may result in prevention of chronic kidney disease especially that ages between 40-49 years old are considered relatively younger ages if compared to other worldwide numbers.

Table 1:-Baseline criteria of study subject

\begin{tabular}{|c|l|l|}
\hline & Mean \pm SEM & Percentage \\
\hline Weight (Kg) & 77.44 & - \\
\hline Male & 65.1 & - \\
\hline Flood pressure & - & \\
High & - & $68 \%$ \\
Normal & - & $32 \%$ \\
\hline Years of dialysis & - & $24 \%$ \\
$2-4$ y & - & $12 \%$ \\
$4-6$ y & - & $40 \%$ \\
$8-8 y$ & - & $12 \%$ \\
$10-12 \mathrm{y}$ & - & $4 \%$ \\
$>12 \mathrm{y}$ & - & $4 \%$ \\
\hline
\end{tabular}




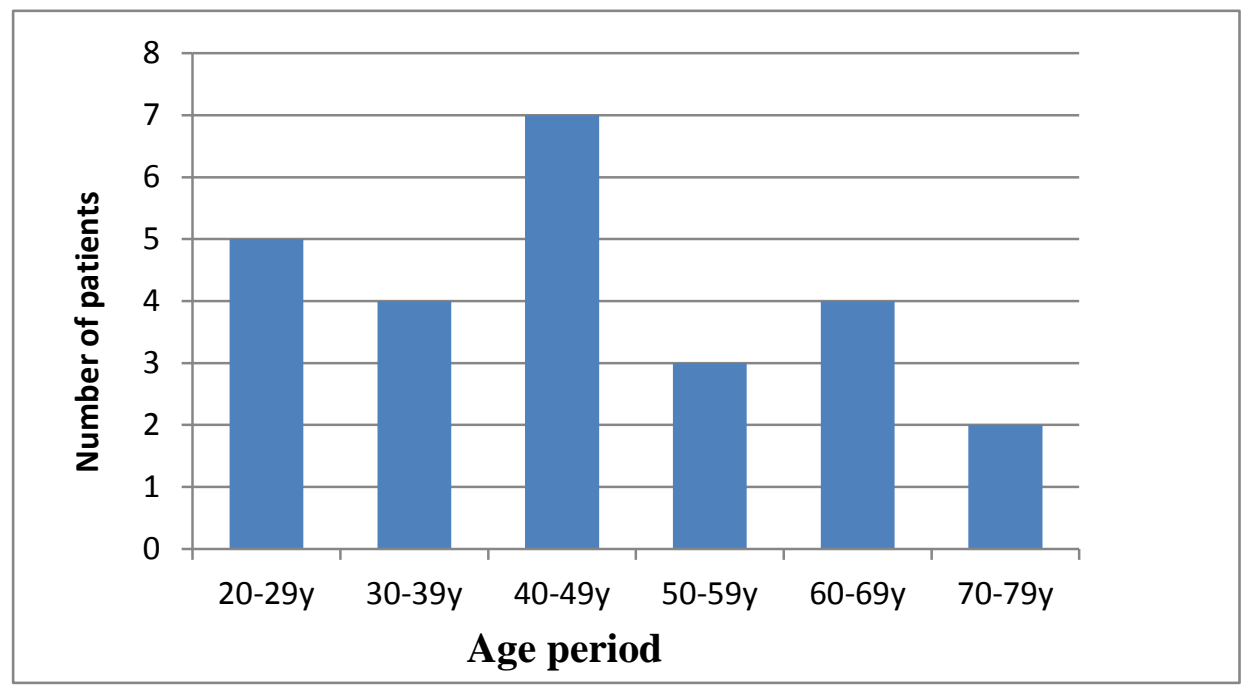

Figure 1:-Distribution of study sample over different age periods.

Table 2:-Laboratory tests results.

\begin{tabular}{|l|l|l|l|}
\hline Clinical indicator & $\begin{array}{c}\text { Average value at time of } \\
\text { starting hemodialysis }\end{array}$ & Average value at time of study & \multicolumn{1}{|c|}{ Reference value } \\
\hline WBC & $6.825^{*} 10^{\wedge} 9$ & $6.516^{*} 10^{\wedge} 9 \neq$ & $4.00-11.00 / \mathrm{L}$ \\
\hline HB & 9.796 & $8.752 \ddagger$ & $12.5-18 \mathrm{~g} / \mathrm{dL}$ \\
\hline Phosphate & 8.2332 & $5.6456 \neq$ & $2.5-4.5 \mathrm{mmol} / \mathrm{L}$ \\
\hline Calcium & 7.1688 & $6.7884 \neq$ & $8.4-10.20 \mathrm{mmol} / \mathrm{L}$ \\
\hline Sodium & 132.252 & $128.788 \neq$ & $137.0-145 \mathrm{mmol} / \mathrm{L}$ \\
\hline Creatinin & 11.512 & $11.364 \neq$ & $0.70-1.20 \mathrm{mg} / \mathrm{dL}$ \\
\hline Urea & 123.188 & $138.8 \neq$ & $10.0-50.0 \mathrm{mg} / \mathrm{dL}$ \\
\hline Albumin & 3.772 & 3.632 & $3.5-5.5 \mathrm{mg} / \mathrm{dL}$ \\
\hline Glucose & 99.52 & $110.88 \neq$ & $70-99 \mathrm{mg} / \mathrm{dL}$ \\
\hline
\end{tabular}

₹ Significant at $\mathrm{p}<0.05$

\section{References:-}

1. Kadiki, O.A., Roaeid, R.B. (2001) Prevalence of diabetes mellitus and impaired glucose tolerance in Benghazi Libya. Diabetes Metab., 27(6):647-654

2. Rao, G.M. (1992) Diabetes mellitus in Libya: a retrospective study. Indian J. Med. Sci., 46(6):174-181

3. Goleg, F.A., Kong, N.C. and Sahathevan, R. (2014) Dialysis-treated end-stage kidney disease in Libya: epidemiology and risk factors. Int. Urol. Nephrol., 46(8):1581-1587

4. Alashek, W.A., Mclntyre, C.W. and Taal, M.W. (2011) Provision and quality of dialysis services in Libya. Hemodial. Int., 15(4):444-452

5. Alashek, W.A., Mclntyre, C.W. and Taal, M.W. (2012) Epidemiology and aetiology of dialysis-related endstage kidney disease in Libya. BMC Nephrol., 13(33):1-7

6. Alashek, W.A., Mclntyre, C.W. and Taal, M.W. (2013) Detreminants of survival in patients receiving dialysis in Libya. Hemodial. Int., 17(2):249-255

7. Usta, A., Shawish, T., Mishra, A., Ehtuish, E.F., Ajaj, H., Milud, N., Shebani, A., Abdulmola, T. and Tajori, U. (2008) Living related kidney transplantation in Libya: a single center experience. Transplant. Proc., 40(10):3428-3433

8. Ehtuish, E.F., Abouna, G.M., Shebani, A.H., Abdulmola, T.S. and Shawesh, T.Z. (2006) Kidney transplantation in Libya: a North African and Middle Eastern perspective. Exp. Clin. Transplant., 4(1):425-428

9. Jondeby, M.S., De-Los Santos, G.G., Al-Ghamdi, A.M., Al-Hawas, F.A., Al-Sulaiman, M.H. and Al-Khader, A.A. (2001) Caring for hemodialysis patients in Saudi Arabia. Past, present and future. Saudi Med. J., 22(3):199-204 
10. Auer, J., Oliver, D.O. and Winearls, C.G. (1990): The quality of life of dialysis patients treated with recombinant human erythropoietin. Scand. J. Urol. Nephrol., Suppl 131: 61-65

11. Delano, B.G., (1989) Improvements in quality of life following treatment with r-HuEPO in anemic hemodialysis patients. Am. J. Kidney Dis., 14[2 Suppl 1]:14-18

12. Avram, M.M., Blaustein, D., Fein, P.A., Goel, N., Chattopadhyay, J. and Mittman, N. (2003) Hemoglobin predicts long-term survival in dialysis patients: A 15-year single-center longitudinal study and a correlation trend between prealbumin and hemoglobin. Kidney. Int., Suppl 87: S6-11

13. Besarab, A., Bolton, W.K., Browne, J.K., Egrie, J.C., Nissenson, A.R., Okamoto, D.M., Schwab, S.J and Goodkin, D.A. (1998) The effects of normal as compared with low hematocrit values in patients with cardiac disease who are receiving hemodialysis and epoetin. N. Engl. J. Med., 339(9): 584-590

14. Eschbach, J.W., Abdulhadi, M.H., Browne, J.K., Delano, B.G., Downing, M.R., Egrie, J.C., Evans, R.W., Freidman, E.A., Graber, S.E., Haley, N.R., Korbet, S., Krantz, S.B., Lundin, A.P., Nissenson, A.R., Ogden, D.A., Paganini, E.P., Rader, B., Rutsky, E.A., Stivelman, J., Stone, W.J., Teschan, P., Van Stone, J.C., Van Wyck, D.B., Zuckerman, K. and Adamson, J.W. (1989) Recombinant human erythropoietin in anemic patients with end-stage renal disease. Results of a phase III multicenter clinical trial. Ann. Intern. Med., 111:992-1000

15. Santos, S.F.F., Peixoto, A.J. (2010) Sodium balance in maintenance hemodialysis. Semin. Dial., 2:549-555. 